\title{
FROM THE MEANING TRIAD TO MEANING HOLISM: UNIFYING LIFE'S MEANING
}

\author{
JOSHUA SEACHRIS
}

\begin{abstract}
Claims that talk of life's meaning is misguided, unmanageable or, worse, nonsensical, are overblown. Such claims especially track the cosmically focused the meaning of life. "The meaning of life" is perfectly intelligible, and is centered on a cluster of ideas encapsulated by what I call the "meaning triad." One component of this triad- $\mathrm{I}^{\mathrm{I}_{\mathrm{EANIN}}}$ - provides the hermeneutical and conceptual resources for understanding the question "What is the meaning of life?" as asking for a single thing, in contrast to amalgam and pluralist views. I will investigate the meaning triad en route to defending meaning of life holism.

Key words: meaning; sense-making; purpose; significance; life's meaning; meaning of life
\end{abstract}

\section{The meaning triad}

Meaning-talk is ubiquitous in everyday discourse. Ordinary ways of communicating reveal patterns that have important implications for theorization on life's meaning, both meaning in life (MinL) and the meaning of life (MofL). ${ }^{1}$ Garden variety uses of "meaning" tend to cluster around three basic ideas: (1) intelligibility, sense-making, clarification, or coherence, (2) purpose, and (3) significance or value, each of which is captured in the examples below:

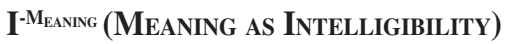

1. What you said didn't mean a thing.

2. What did you mean by that statement?

3. Do you know what I mean?

4. What did you mean by that face? (overlaps with purpose)

5. What is the meaning of that book? (what is it about?)

6. What is the meaning of this? (for example, when asked upon returning home to find one's house ransacked)

\footnotetext{
1 A now entrenched distinction in the field.
}

DE GRUYTER 


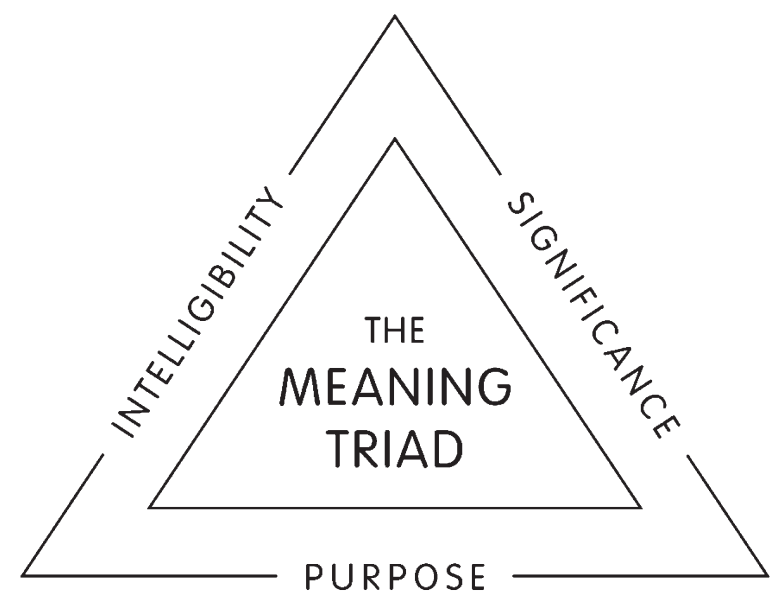

$\mathbf{P}^{-M_{\text {Eaning }} \text { (Meaning as Purpose) }}$

7. What did you mean by that face? (overlaps with intelligibility)

8. The tantrum is meant to catch his dad's attention.

9. What is the meaning of that book? (why was it written?)

10 . I really mean it!

11. I didn't mean to do it. I promise!

\section{$\mathrm{S}^{\text {-Maning (Meaning as Significance) }}$}

12. That was such a meaningful conversation.

13. This watch really means something to me.

14. That is a highly meaningful event in the life of that city.

15. That is a meaningful finding.

16. That is a meaningless statistic.

17. You mean nothing to me.

$I^{-M_{\text {EANING }}}$

$\mathrm{I}^{-\mathrm{M}_{\mathrm{EANIG}}}$ is an important ordinary sense of meaning and connotes ideas like intelligibility, sense-making, clarification, and coherence. Something has meaning if it makes sense; it lacks meaning if it does not. One way of understanding sense-making is through the idea of proper fit. Things (words, concepts, propositions, but also events and states of affairs) make sense and are meaningful if they fit together properly; if they lack fit, they make no sense (or at least not the relevant kind of sense) and are meaningless. This applies narrowly (for example, it makes no sense to ask, "What is larger than the largest object?" It does not fit with the concept of the largest object to ask what is larger), but it has a broader application too. We say things like: 
1. It does not make sense to hit 9-iron off the tee at a 600 yard par five.

2. Asking philosophy students to perform long-division on their midterm makes no sense. ${ }^{2}$

In each of these situations, we perceive a lack of fit - a lack of fit between shot and club choice and between the kind of question asked and reasonable expectations about what one will find on a philosophy exam. There is an absurdity here. Perceiving this weaker lack of fit will be a product of beliefs, norms, and other epistemic, evaluative, and social commitments. Therefore, determining whether or not something, in fact, involves a lack of fit in this broader sense often will be a messier task than in cases of narrow sense-making.

Ascertaining meaning, then, is often about fitting something into a larger context or whole: words into sentences, paragraphs, novels; musical notes into measures, movements, and symphonies (i.e., the movement from mere sound to music), parts of a photograph within the entire photograph. Meaning is about intelligibility within a wider frame (cf. Svendsen, 2005 , p. 29). Dissonance results when there is a lack of such intelligibility. It is much the same with life's meaning. We can plausibly view our requests for the meaning of life as attempts to secure the overarching framework or context through which to make sense of our lives in this universe. ${ }^{3}$ Our focus is on existentially weighty matters that define and depict the human condition: questions and concerns surrounding origins, purpose, significance, value, suffering, and death and destiny. We want answers to our questions about these matters, and want these answers to fit together in an existentially satisfying way. We want life to make sense, and when it does not, we are haunted by the specter of meaninglessness.

One thinks of Shakespeare's Macbeth who laments that the tale of the world is one that is "told by an idiot, full of sound and fury, signifying nothing." ${ }^{4}$ One way to understand Macbeth's words is that he laments that life does not make sense, that its various aspects, especially those with existential gravitas, fail to fit together properly. Could it really be that no deep rhyme or reason frames the existentially profound stuff of life? Does it unfold on a Samuel Beckett-style stage? Are our joys, sorrows, and deep hopes_-and all that induces them-simply accidental collocations of atoms that are here today and then quickly gone and forgotten forever? (cf. Russell, 1957, p. 107). Surely, this is absurd; it makes no sense. No narrow logical norms are violated, of course, but a broader, though more existentially worrisome, lack of fit surfaces.

Or, take Camus' concept of the absurd - the profound discrepancy between the intense human desire for happiness and understanding to coalesce and the utter silence of the universe to quench such desire (see Camus, 1991). For Macbeth and Camus, life lacks an

\footnotetext{
2 What is less clear, however, is whether it is appropriate to call these situations meaningless. Here, we must ask whether or not all instances of making sense or not making sense allow for a substitution of "meaningful" or "meaningless." It is meaningless to ask what is larger than the largest object. Is it also meaningless to hit 9-iron off the tee at a 600 yard par five?

3 Psychologists, too, recognize the importance of sense-making to the human drive for meaning. According to social psychologist Thomas Gilovich, "We are predisposed to see order, pattern, and meaning in the world, and we find randomness, chaos, and meaninglessness unsatisfying. Human nature abhors a lack of predictability and the absence of meaning" (1991, p. 9).

4 Shakespeare, Macbeth, Act 5, Scene 2. Of note, some modern versions of the text substitute "meaning" for "signifying."
} 
important kind of $\mathrm{I}^{-\mathrm{M}_{\mathrm{EANNG}}}$, at least an existentially satisfying one. Life is meaningless because its various parts do not (broadly) fit together. Some feature(s) of the universe appear not to fit with some other feature(s) given the purported ontological-normative shape of it all. Acquiring a grand naturalistic sense-making framework or metanarrative would not suffice to render life intelligible in the way they desire. Despite providing sense-making at one level, it does not allow for a fittingness between deep human longings and reality in the way that Macbeth, Camus, and countless others want. For this reason, many think that a naturalistic story of the universe is, at heart, an absurd tale told by an idiot. ${ }^{5}$

This shows that sense-making, broadly construed, can be variously understood, and that one way of thinking about it becomes prominent when life's meaning is in view. Naturalism, no doubt, offers a sense-making explanation or meta-narrative of life. It provides a kind of intelligibility, a way of fitting things together, even many of those things that are part and parcel of the human condition. Even with this framework in hand, however, those who worry about life's meaning, like Macbeth and Camus, will still think that life does not make sense or is absurd given naturalism. For them, life still lacks an important kind of $\mathrm{I}^{-\mathrm{M}_{\mathrm{EANN}} \text {. It fails }}$ to fit together properly. Why? Because deep human longings, especially along significance, value, and purpose axes, and deep hopes for ultimate justice and a lasting place for love and felicity are stubborn. These shalom-esque longings do not fit (or at least do so in thinner form) within a naturalistic universe.

The human search for meaning, then, is not so easily disentangled from our capacity (and propensity in our more reflective moments) to take up meta-perspectives, to set and evaluate our lives within wider frames, even cosmic ones, whether theistic, otherwise religious but non-theistic, or naturalistic, and to ask what sort of sense they make and how they fit within the ontological-normative architecture of those frames. I am skeptical that we can fully understand what is involved in the human search for meaning if we neglect this. I briefly consider this point again in the final section of the paper.

Two final, critical points need making before we move on. First, in some-though not all—ordinary contexts where we seek $\mathrm{I}^{-\mathrm{M}_{\mathrm{EANNG}}}$, we think that rendering something intelligible is not sufficient for such meaning. We think that truth must be added to intelligibility. Truth, of course, is not a necessary condition for bare intelligibility (works of fiction, for example, can be perfectly intelligible), but it is probably required for full-blown $\mathrm{I}^{-\mathrm{M}_{\mathrm{EANIN}}}$ in some contexts. For example, if I ask my children, "What is the meaning of this?" in response to walking in on their fight, they could render their fight intelligible by telling me a coherent story about it and how it unfolded that is nonetheless false. I would be unsatisfied with this. Though they have conveyed intelligibility, and though their explanation is meaningful as such at one level, they have not conveyed the full-blown meaning that I seek. I want the

\footnotetext{
5 Optimistic naturalists will demur. Pessimistic naturalists and theists have inflated expectations regarding fit so the argument goes. They set the meaning bar too high. This rift reveals deep disagreement about (a) what needs to fit together and (b) what is necessary for it to fit together. Naturalistic metanarratives, no doubt, make sense of the world at one level. For pessimistic naturalists and theists, however, the human heart does not fit within the naturalist universe and a deflationary

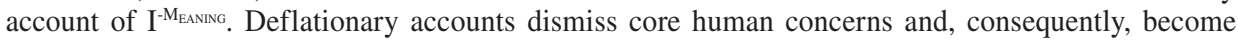
consistent only by denying what does not fit, for example, near ubiquitous human longings for postmortem survival and ultimate justice.
} 
meaning of the fight, not merely a possible meaning of the fight. Similarly, we want the meaning of life. ${ }^{6}$

Second, especially when life's meaning is in view, we may find ourselves with the opposite scenario-what if the truth is unwelcome? In the former case, the kind of sensemaking we desire requires truth. In this case, ex hypothesi, what if the truth about the world is accompanied by the visceral reaction that life makes no sense, that it is absurd, that what is most important to us does not fit with what we are told is true about the universe? Such a charge of absurdity perhaps finds motivation in the view that the Medieval transcendentals of truth, goodness, and beauty ultimately coalesce, that the ultimate truth about the universe could never be terrible. This reveals two kinds of sense-making in deep tension, one of which is complicated by human psychology and existential longings. Setting aside these final complicating matters, it remains that $\mathrm{I}^{-\mathrm{M}_{\mathrm{EANING}}}$ provides a compelling route to interpreting the traditional formulation of the question of life's meaning- "What is the meaning of life?" I return to this point below in the section on the mechanics of meaning holism.

$P^{-M_{E A N I N G}}$

Requests for meaning are very often requests for purpose. Here, two categories of meaning are in play, though at different levels: $\mathrm{I}^{-\mathrm{M}_{\mathrm{EANING}}}$ and $\mathrm{P}^{-\mathrm{M}_{\mathrm{EANING}}}$. Rendering something intelligible is itself an important way of recognizing meaning, and when what is made intelligible is

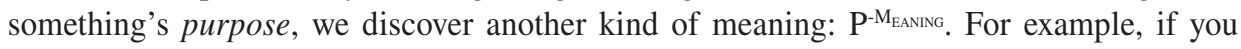
ask what is the meaning of that face $\mathrm{I}$ just made, I provide $\mathrm{I}^{-\mathrm{M}_{\mathrm{EANING}}}$ through a sense-making explanation, and my explanation will reveal $\mathrm{P}^{-\mathrm{M}_{\mathrm{EANING}}}$ given that I will likely appeal to my intentions. I made that face for the purpose of signaling my interest in what you had to say; that is what my face meant. Though requests for $\mathrm{P}^{-\mathrm{M}_{\mathrm{EANIN}}}$ trivially presuppose requests for

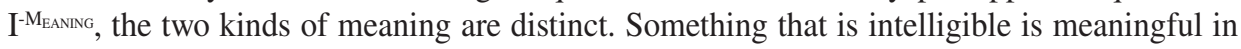
virtue of being intelligible, and when such intelligibility includes information about purposes

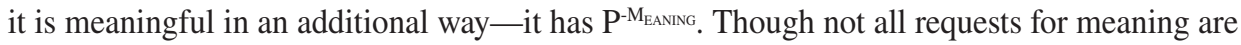
requests for $\mathrm{P}^{-\mathrm{M}_{\mathrm{EANIN}}}$, all requests for $\mathrm{P}^{-\mathrm{M}_{\text {EAnIIG }}}$ presuppose a more basic request for $\mathrm{I}^{-\mathrm{M}_{\mathrm{EANING}}}$.

The connection between $\mathrm{P}^{-\mathrm{M}_{\mathrm{EANIN}}}$ and life's meaning has always been largely taken for granted, so I will say very little here. If you ask people what they think the question "What is the meaning of life?" means, they will very often respond that it is about the purpose(s) of life. Many assume that there is a cosmic purpose around which we ought to, in large part, order our lives, and such a purpose presupposes transcendent agency as its source. One might reject cosmic purpose, though, and still frame questions about life's meaning as largely about purpose. Meaningful life, in this case, is thought to be primarily about structuring one's life around self-determined purposes.

It is worth briefly discussing a subtly different shade of $\mathrm{P}^{-\mathrm{M}_{\mathrm{EANING}}}$ that occurs in ordinary discourse. We use meaning (or meant) to contrast willful action (done on purpose) from non-

\footnotetext{
${ }^{6}$ For those who are uncomfortable with requiring a truth condition in some instances of $\mathrm{I}^{-\mathrm{M}_{\mathrm{EANING}} \text {, we }}$ could say that we often want more than I- $\mathrm{M}_{\mathrm{EANING}}$; we want a meaning that is true, not that the concept of $\mathrm{I}^{-\mathrm{M}_{\mathrm{EANING}}}$ includes truth. Still, in many ordinary contexts where sense-making meaning is sought, we do not think that we have the meaning we seek if what we have is not also true.
} 
willful action (done by accident). We say things like, "I really mean it" to indicate the 'full' operation of our will. ' Our volitional architecture is wholly in play when we take oaths or make vows. These acts, especially, we do on purpose. Alternatively, our child might say, "I didn't mean it, I promise!" to indicate that she did not intend to spill her glass of milk.

This sense of "meant" is also relevant for life's meaning. We want sufficient autonomy, and when it is absent or severely mitigated, we worry about the meaningfulness of our lives (cf. Mawson, 2016b). ${ }^{8}$ Most of us do not want to walk through life haphazardly, nor in a way that is largely determined by factors outside of our own consent. One likely aspect of meaningful life, then, is life lived with our wills sufficiently engaged, one lived on purpose. These two shades of $\mathrm{P}^{-\mathrm{M}_{\mathrm{EANNG}}}$ are probably related. We want to really mean it as we select and align our lives with aims that will provide the salient structural rhythms to our day-to-day existence. In other words, we do not want to be alienated from the purposes that guide our lives.

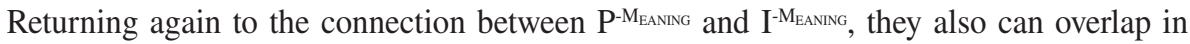
virtue of the structure provided by goals and aims being an important part of the framework through which life fits together and makes sense. Lives that fit together and make sensemeaningful lives-are those that are sufficiently teleological. Working to attain goals at various levels of life-centrality is likely a facet of life properly fitting together and therefore being meaningful. Teleological threads connecting discreet life episodes are then necessary

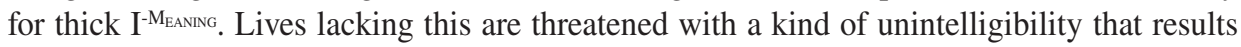
from being insufficiently structured by a telos. In the words of Alasdair MacIntyre:

When someone complains...that his or her life is meaningless, he or she is often and perhaps characteristically complaining that the narrative of their life has become unintelligible to them, that it lacks any point, any movement toward a climax or a telos (MacIntyre, 2007, p. 217).

$S^{-M_{E A N I N G}}$

Meaning often conveys the idea of significance, and significance tracks a related cluster of notions like mattering, importance, impact, salience, being the object of care and concern, and value, depending on context. In saying that something has $\mathrm{S}^{-\mathrm{M}_{\mathrm{EANING}}}$, we often convey that it has a kind of normative gravitas, though there are ways for something to be significant that are probably not normative (for example, the idea of making a splash). We contrast trivial discussions about the mundane with deep discussions about important matters, referring to the latter as meaningful or significant. Physical objects deeply enmeshed in our life stories are meaningful. Songs associated with a particularly poignant season in life matter to us, for example, our first love. We view actions and events that have salient implications as significant, and in cases where that significance has a positive valence, as meaningful. ${ }^{9}$

\footnotetext{
7 Since I have ordinary discourse in view, the position one takes in debates over free-will is irrelevant here.

8 Following Sartre, some worry that God's existence and, especially, God's intentions for our lives would severely threaten our capacity to live our lives on purpose.

9 Negatively valenced events are often significant; whether they are meaningful is less clear. For
} 


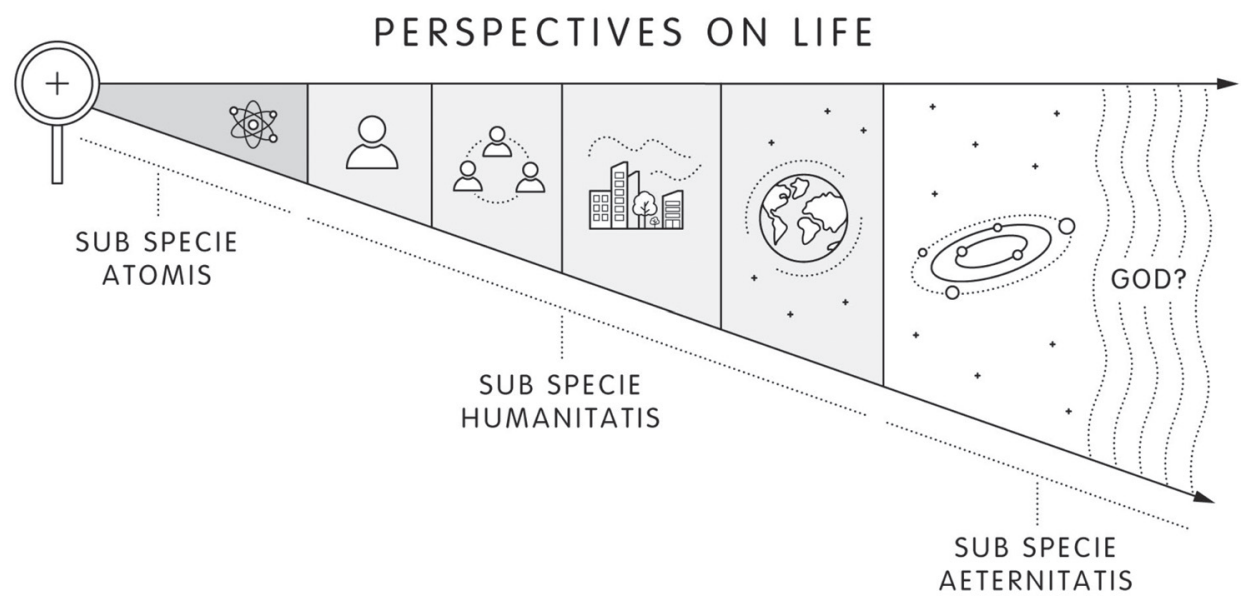

Finding the cure for that disease was meaningful because it had such a large positive impact within a certain frame of cares and concerns. $\mathrm{S}^{-\mathrm{M}_{\mathrm{EANIN}}}$ is also in view in cases where some piece or set of data crosses a threshold of salience against background information. That such a large percentage of the population living under certain conditions is getting a particular disease is statistically significant or statistically meaningful. ${ }^{10}$

Alternatively, when something matters very little or not at all to us, we say, "That means nothing to me." It was just a meaningless conversation; it was inconsequential. That game did not matter because the playoffs were already set. The wrapping paper does not matter, what is on the inside counts. That piece of information is not meaningful relevant to the aims and questions guiding one's inquiry. Spending your life sitting on the couch and watching reruns on Netflix is meaningless; you do nothing that matters, you do nothing of importance or value, and so on.

It is worth pointing out that something's significance is often and largely gauged in relation to a perspective, horizon, or point of reference, all of which can be dynamic. Something that is significant from one vantage point may (and often does) lose its significance when viewed from a broader horizon. Getting a splinter at age four is significant

example, the EF5 tornado that destroyed the town of Greensburg, KS, on the evening of May 4, 2007, was highly significant-it was an important, impactful, extremely salient event with far-reaching implications for the life of that community. But was it meaningful? Meaningful (at least under the category of $\mathrm{S}^{-\mathrm{M}_{\mathrm{EANNG}}}$ ) seems to have a distinctly positive quality that significance simpliciter lacks (Of course, the tornado is crucial to I'MenNing in the sense that one cannot now understand the story of Greensburg, KS, apart from that event). Furthermore, if the $\mathrm{S}^{-\mathrm{M}_{\text {EANINGUL }}}$ is something like significance + positive valence, then there is reason to think that someone whose life is highly significant, but characterized by deep and systemic moral deficiency (e.g., Hitler) lives a severely impoverished life with respect to meaning, even though it is important, matters greatly, and makes a large impact. In this way, it may be that meaning and morality (and other values) are inseparable.

${ }^{10}$ Here, we see a connection between $\mathrm{I}^{-}$and $\mathrm{S}^{-\mathrm{M}_{\mathrm{EanNG}}}$. 
(at least from a four-year old's perspective!). When looking back at age forty-three, its significance wanes. Most events important enough to make it into local lore will not matter enough to be included in a national history, let alone world (and, especially, cosmic) history. One quickly sees resources available from which to generate pessimistic meaning of life concerns vis-à-vis human significance as one broadens horizons, eventually terminating in a cosmic — and naturalistic_-sub specie aeternitatis perspective. ${ }^{11}$

$\mathrm{S}^{-\mathrm{M}_{\text {EANING }}}$ is often distinctly normative and person-al. When we say that something is meaningful in the sense of being significant, important, or mattering, we make a kind of evaluative claim. Additionally, $\mathrm{S}^{-\mathrm{M}_{\mathrm{EANING}}}$ is connected with being the object of a person's evaluations, cares, and concerns. Things are, most naturally, significant to someone.

Insofar as meaning is thought to have an affective dimension, that dimension likely

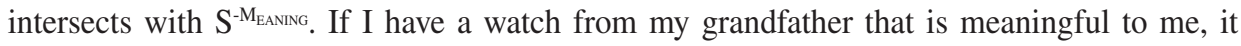
has value, it matters, and affective states fitting a certain psychological profile, such as being deeply stirred or moved, often accompany assessments of value and mattering. Though I am skeptical that this makes these affective states a further type of meaning or constitutive of meaning, they probably reliably track instances of, especially, $\mathrm{S}^{-\mathrm{M}_{\text {EANING }} \text {. }}$

Like the other two broad categories of meaning, $\mathrm{S}^{-\mathrm{M}_{\mathrm{EANING}}}$ is relevant for life's meaning. In broad terms, one way of construing meaningful life is as a life that matters and has positive valence. This, of course, admits of various understandings of mattering that, at one level, might track the standard objectivist, subjectivist, hybrid theorist, supernaturalist dialectic - according to whom it matters and according to what standard. Additionally, some find it difficult to separate personal and cosmic concerns over significance. Cosmic concerns, for many, are also intensely personal. If the universe as a whole lacks significance, some worry that their individual lives lack significance, or at least the kind that they think a deeply meaningful life requires.

\section{MinL and Ordinary Senses of "Meaning”}

Setting aside until further reflection on how these ordinary senses of "meaning", especially

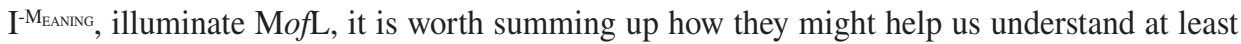
the broad structural contours of MinL:

$\mathbf{I}^{-\mathbf{M} i n \mathbf{L}}=$ An intelligible life; one that makes sense (broad sense-making), that fits together properly, and exhibits a kind of coherence (for example, relationally, vocationally, morally, spiritually, and so on), perhaps even narrative coherence.

$\mathbf{P}^{-M i n L}=$ A life saliently oriented around purposes, goals, and aims, and lived on purpose in which the person's autonomy is sufficiently engaged.

\footnotetext{
${ }^{11}$ People generally do not worry about being cosmically insignificant in a theistic universe, though presumably it too would be old and immense. I will not enter the debate here about whether such worries about cosmic significance are themselves justified. For relevant recent work on the topic, see Seachris (2013), Kahane (2014), and Landau (2011, 2014).
} 
$\mathbf{S}^{- \text {Min } \mathbf{L}}=$ A life that matters (and has positive valence)—intrinsically in virtue of the kind of life that it is and extrinsically in virtue of its implications and impacts, especially within the narrow (e.g., familial) and broad (e.g., cultural, spiritual) relational webs of which the person is a part.

Two quick, concluding observations are in order. First, there is a reason why people initially ask about the meaning of life or meaningful life as such, as opposed to framing such questions in terms of purpose or significance, though those are important connotations of "meaning." Although "meaning's" semantic range can be unwieldy, that range is an important clue as to what we ask via how we ask it. Because its semantic range includes the ideas of intelligibility, purpose, and significance, it is the most apt term to capture all that concerns us when we inquire into life's meaning. Neither purpose nor significance alone captures all of these ideas, but meaning does.

Second, though one can adopt a version of the amalgam approach and view intelligibility, purpose, and significance as largely distinct ways of thinking about what life's meaning involves, I suspect that there is a more compelling organic story to be told about both $\mathrm{MinL}$ and MofL. We should not view these broad categories of meaning conjunctively or additively (or even as just loosely connected) only; rather we should think of them as having an organic relationship. Here is one way in which all three senses of meaning might coalesce and bring into relief the full structural contours of meaningful life (MinL) in a unified way:

$\operatorname{Min} \mathbf{L}=$ A life that makes sense, that fits together properly $\left(\mathrm{I}^{-\mathrm{M}_{\mathrm{EANIN}}}\right)$ in virtue of appropriate orientation around purposes $\left(\mathrm{P}^{-\mathrm{M}_{\mathrm{EANN}}}\right)$, other (atelic) activities, and relationships that matter and have positive valence $\left(\mathrm{S}^{\left.-\mathrm{M}_{\mathrm{EANN}}\right)}\right)^{12}$

\section{The mechanics of meaning holism \& the meaning of life}

$\mathrm{I}^{-\mathrm{M}_{\mathrm{EANIG}}}$ provides indispensable hermeneutical and conceptual resources for understanding the question, "What is the meaning of life?" in a way that (1) views it as a singular, intelligible, answerable request (contra amalgam approaches), (2) organically secures conceptual space for each of the other ordinary senses of meaning that are relevant to understanding life's meaning, and (3) links epistemic and normative concerns at cosmic and individual levels about how to live a meaningful life in light of our place within the grand scheme of things.

$\mathrm{I}^{\mathrm{M} \text { EANIG }}$ is clearly in view in many ordinary contexts that share relevant similarities with those where our focus is on life's meaning. We are confronted with circumstances that we do not yet sufficiently understand, in which case we might naturally respond by asking, "What's

\footnotetext{
${ }^{12}$ Psychologists, too, are increasingly coalescing on this tripartite understanding of meaning. For example, psychologist Michael Steger proposes a definition of meaning in life that incorporates a similar triad that prioritizes sense-making: "Meaning is the web of connections, understandings, and interpretations that help us comprehend our experience and formulate plans directing our energies to the achievement of our desired future. Meaning provides us with the sense that our lives matter, that they make sense, and that they are more than the sum of our seconds, days, and years." (Steger, 2012, p. 165). See also King, Heintzelman, and Ward (2016) and Martela and Steger (2016).
} 
this all about?" or "What's going on here?" or "What happened?" or "What's happening?" or "What does this mean?" or "What is the meaning of this?" In asking such questions, we

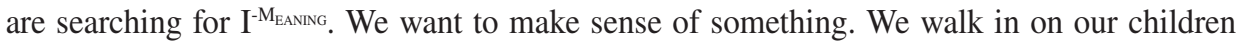
fighting and demand: "What is the meaning of this?"13 Mary Magdalene and Mary the mother of James find a stone rolled away from a Roman guarded tomb. The burial linens are there, but Jesus' body is nowhere to be found. One can imagine them thinking, "What is the meaning of this?" We naturally invoke the formula "What is the meaning of $x$ ?" in situations where $x$ is some fact, event, phenomena, or cluster of such things, and about which we want to know, in the words of New Testament scholar, N. T. Wright, its "implication in the wider world within which this notion makes the sense it makes" (Wright, 2003, p. 719). Such requests track our desire to make sense of a situation, to render it intelligible with the further aim of acting appropriately in response-a kind of epistemic map to aid in practical, normative navigation.

Taking our cue from these ordinary examples involving $\mathrm{I}^{-\mathrm{M}_{\mathrm{EANI}}}$, to inquire about life's meaning is plausibly understood as asking something similar to our requests for the meaning of our children's scuffle or of the empty tomb. Over the course of our existence, we encounter aspects of the world that have a kind of existential gravitas in virtue of their role in defining and depicting the human condition. They capture our attention in a unique way. The word "life," then, is a rough marker for these existentially-weighty aspects, aspects of life that give rise to profound questions for which we seek an explanatory framework (perhaps even a narrative framework) in order to make sense out of them. These aspects of the world are akin to the portion of the scuffle and empty tomb above to which we already have limited informational access: yelling and throwing in the case of the scuffle, and the various pieces and clues observed at the empty tomb. Similar to the parent or Mary Magdalene in those situations, we lack important parts of life's context, and we desire to fill in these existentially relevant epistemic gaps, and then live accordingly. We are in search of life's meaning, where that meaning is, at center, a kind of $\mathrm{I}^{\text {-Meaning }}$ that provides an overarching sense-making framework for answering and fitting together answers to our questions about origins, purpose, significance, value, suffering, and destiny. The meaning

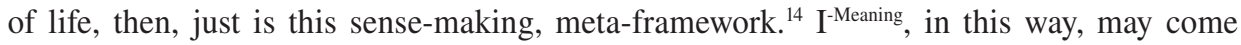
hermeneutically prior to the other parts of the meaning triad, $\mathrm{P}^{-}$and $\mathrm{S}^{- \text {Meaning, }}$, for framing and understanding the sort of request we are making. Of note is that we do not first ask

\footnotetext{
${ }^{13}$ In the case of our children fighting, we might also ask, "Why are you fighting?" The "why" version of this request, though, invites more than one interpretation and is subject to a kind of Aristotelian causal analysis. We can think of this as a request for purpose information: our children are fighting in order to solve a problem (albeit in a misguided and unproductive way). On another interpretation, our children are fighting because of the circumstances that led up to the fight. The difference, then, is between fighting for or to (emphasis on purpose) and fighting because (emphasis on sense-making, which may, of course, include some information about purpose). But surely the natural way to understand the request, "Why are you fighting?" is not so much as asking what are you fighting in order to accomplish? but, rather, how did the fight start? The request is largely backward rather than forward facing.

${ }^{14}$ See the end of the section on $I^{M_{\text {EANNG }}}$, though, for how the various understandings of broad sensemaking and things fitting together properly complicate this. See also the final section on sense-making.
} 
about the purpose of life or the significance of life, we first ask about the meaning of life. "Meaning's" semantic range may be more conceptually fruitful than either "purpose's" or "significance's" in this context, and the sense-making portion of that semantic range allows us to see the traditional formulation of the question as asking a single thing, albeit one that targets multiple, but connected ideas intersecting directly and indirectly with purpose and significance.

Although $\mathrm{P}^{-}$and $\mathrm{S}^{-\mathrm{M}_{\mathrm{EANING}}}$ accompany $\mathrm{I}^{-\mathrm{M}_{\mathrm{EANING}}}$ to round out the meaning triad, neither seems to make the same kind of organic conceptual space for the other senses of meaning.

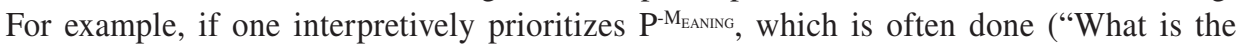
purpose of life?"), then one's focus will be on a narrower question initially, and one whose answer does not as naturally accommodate the other senses of meaning nor other important questions related to life's meaning. A question about life's purpose is not, at first, a question about life's significance or life's intelligibility. But a question about life's meaningunderstood first as $\mathrm{I}^{-\mathrm{M}_{\text {EANing }}}$-in which we are trying to make sense of life, is a question wrapped up with purpose, significance, and the rest of the territory encapsulated in our questions and concerns about meaning, given the scope of our existential cares and concerns of which we seek to make sense. ${ }^{15}$

The centrality of $\mathrm{I}^{-\mathrm{M}_{\mathrm{EANIN}}}$ for understanding the question "What is the meaning of life?" is also evident by considering another form that the question sometimes takes: What's it all about? "What's it all about?" can be substituted more naturally for "What is the meaning of life?" than it can for, for example, "What is the purpose of life?" "What's it all about?" straightforwardly appears to ask for something like $\mathrm{I}^{-\mathrm{M}_{\mathrm{EANN}}}$. We are thrust into existence, and at some point we have deep questions about it all. How did the universe come to be? Is there a reason why we are here, a reason of a fundamentally different kind than what physics, chemistry, and biology provide? How should we live? Are we significant? To whom? Are some things more valuable than others? Where does value even come from? Why do we suffer? How is it all going to end? In and through our human experience of great joy, intense sorrow, and sometimes angst-laden bewilderment, we want to know how it all fits together. We desire to make sense of it all. We seek the $\mathrm{I}^{-\mathrm{M}_{\mathrm{EANIG}}}$ of it all.

The concept of worldview lends further evidence for the claim that life's meaning is, first, about sense-making. Worldviews are, no doubt, connected with life's meaning; on my view, they are straightforwardly putative meanings of life. They provide answers to the

\footnotetext{
${ }^{15}$ One might deny the priority relationship here and respond that both $\mathrm{P}^{-}$and $\mathrm{S}^{-\mathrm{M}_{\mathrm{EANING}}}$ make the same kind of conceptual space for the others. Take $\mathrm{P}^{-\mathrm{M}_{\mathrm{EANING}}}$ for example. Perhaps in giving an account of the purpose(s) of life one thereby renders life intelligible (showing how it all fits together in light of our purpose) and sheds light on human significance. You get both $\mathrm{I}^{-}$and $\mathrm{S}^{-\mathrm{M}_{\mathrm{EANIN}}}$ in answering the question of purpose, just as you get both $\mathrm{P}^{-}$and $\mathrm{S}^{-\mathrm{M}_{\mathrm{EANNG}}}$ in making sense of life. This is worth exploring, though I remain skeptical that either $\mathrm{P}^{-}$or $\mathrm{S}^{-\mathrm{M}_{\mathrm{EANIN}}}$ makes conceptual space for the others as naturally as $\mathrm{I}^{-\mathrm{M}_{\mathrm{EANING}} \text {. }}$ Why? Let us say that someone prioritizes $\mathrm{P}^{-\mathrm{M}_{\mathrm{EANNG}}}$. In order to get the other senses of meaning (and everything else relevant to life's meaning), they will have to build in all the necessary ontological and normative architecture. But in doing this, it begins to look like more than just purpose information is being included. Of course, one could go the amalgam approach route, reject entirely the holist strategy that I am proposing, and say that there is no need to unify all senses of meaning under a single interpretation. That said, I remain skeptical of this amalgamist strategy.
} 
existentially weighty set of questions that bring into relief the human condition. As Milton Munitz notes:

... [people] may say that what they are looking for [when asking the question of life's meaning] is an account of the "big picture" with whose aid they would be able to see not only their own individual personal lives, but the lives of everybody else, indeed of everything of a finite or limited sort, human or not. . . The expression of such a concern involves, at bottom, the appeal to a "worldview" or "world picture." This undertakes to give a description of the most inclusive setting within which human life is situated ... (Munitz, 1993, p. 30).

To offer a worldview, then, is to offer a putative meaning of life (an $\mathrm{I}^{-\mathrm{M}_{\mathrm{EANING}}}$ ) $-\mathrm{a}$ sensemaking framework focused squarely on the set of questions and concerns surrounding origins, purpose, significance, value, suffering, and destiny.

Looking back further into the origin of the worldview concept strengthens the connection between worldview and life's meaning, and offers important clues that a worldview provides a kind of sense-making meaning. Wilhelm Dilthey spoke of a worldview (weltanschauung) as a concept that ". . . constitutes an overall perspective on life that sums up what we know about the world, how we evaluate it emotionally, and how we respond to it volitionally" (Makkreel, 2001, p. 236) ${ }^{16}$ A worldview is motivated out of a desire to answer what he calls the "riddle of existence:"

The riddle of existence faces all ages of mankind with the same mysterious countenance; we catch sight of its features, but we must guess at the soul behind it. This riddle is always bound up organically with that of the world itself and with the question what I am supposed to do in this world, why I am in it, and how my life in it will end. Where did I come from? Why do I exist? What will become of me? This is the most general question of all questions and the one that most concerns me (Dilthey, 1980, pp. 81-82).

Dilthey's cluster of questions that motivate worldview construction are those same questions to which we want answers in seeking life's meaning. Life's meaning is a sense-making framework. It is not a stretch to say that life's meaning is that which worldviews aim to provide.

Hermeneutically prioritizing "meaning" over both "purpose" and "significance" and $\mathrm{I}^{-\mathrm{M}_{\mathrm{EANING}}}$ over both $\mathrm{P}^{-}$and $\mathrm{S}^{-\mathrm{M}_{\mathrm{EANING}}}$ also allows us to interpret the traditional formulation of the life's meaning question as making a singular, intelligible request—and one that makes space for all relevant senses of meaning within that singular request-something that neither $\mathrm{P}^{-\mathrm{M}_{\mathrm{EANING}}}$ nor $\mathrm{S}^{-\mathrm{M}_{\mathrm{EANING}}}$ allows as naturally. This is instructive. I think an important desideratum for any plausible interpretation of "What is the meaning of life?" is that it views the question as making a singular request. Why?-(i) a singular-request interpretation makes most sense of the question's grammatical form, (ii) there is a natural sense of meaning that allows for a singular request interpretation $\left(\mathrm{I}^{-\mathrm{M}_{\mathrm{EANING}}}\right)$, and (iii) this therefore does not force us to conclude that the countless number of people who ask the question in this traditional form are conceptually confused, even if it may not be fully transparent to most why they ask the question in this particular form.

${ }^{16}$ On Dilthey's definition, a worldview possesses three distinct yet interrelated dimensions: cognitive, affective, and practical. Worldviews, therefore, address both MofL and Min L. 
The other senses of meaning do not share $\mathrm{I}^{-\mathrm{M}_{\mathrm{EANING}}}$ 's hermeneutical merits. If one interprets

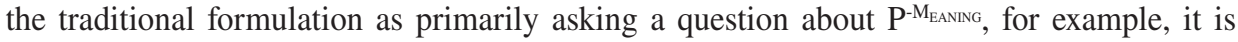
harder to see how it involves a singular request that captures everything we seek vis-à-vis life's meaning since much of what people consider relevant to life's meaning gets left out, or at least is more tenuously connected (origins, significance, suffering, ending). ${ }^{17}$ The only way to get these ideas back into the picture is either to prioritize $\mathrm{I}^{-\mathrm{M}_{\mathrm{EANING}}}$ or opt for a pluralist interpretive strategy like the amalgam approach, in which case the question is not one but many.

The kind of singular, organic interpretive strategy that I propose here is in conflict with the amalgam approach, which is currently the favored higher-order interpretive strategy for understanding the traditional formulation of the question. Roughly, the amalgam approach views the traditional formulation as not making a single request at all, but rather, as a placeholder (some think ill-conceived) for a bunch of other requests that share family resemblances (for discussions of the amalgam thesis, see Hepburn (1966), Baggini (2004), Metz (2007), and Mawson (2016a)). There is something correct in this interpretive approach. In my favored language, there are several senses of meaning operative in life's meaning:

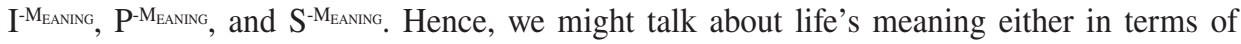
sense-making or purpose or significance (or via cognate ideas). However, taking our cues from what $\mathrm{I}^{-\mathrm{M}_{\mathrm{EANING}}}$ ordinarily involves, it is plausible to view $\mathrm{I}^{-\mathrm{M}_{\mathrm{EANING}}}$ as most fundamental for understanding the request made in "What is the meaning of life?" If we do, we can make the case that the request actually is singular in nature. It asks for one thing: the sense-making framework or explanatory context whose foci are those questions and concerns that define and depict the human condition. In this way, it is like the meaning that Mary Magdalene seeks upon finding the empty tomb and asking, "What is the meaning of this?" or "What's this all about?" or "What is going on here?" We, like her, seek the sense-making framework to understand what happened and is happening vis-à-vis life.

I doubt that the traditional formulation of the life's meaning question is, at bottom, only a conjunctive cluster of distinct questions united simply in virtue of sharing family resemblances. I am strongly inclined to think that it is a single question, the asking of which reveals our desire to make sense of life and existence. We want to fit it all together. The foci of this sense-making activity, no doubt, include purpose and significance, but it is the sense-making framework itself-what makes sense of these and other existentially weighty matters - that is the meaning of life (though see important caveats in the final section). This sense-making framework will include more than just information about purpose and significance; it will illumine origins, suffering, and destiny too.

I have argued that we should prioritize $\mathrm{I}^{-\mathrm{M}_{\mathrm{EANING}}}$ for understanding the request we make in "What is the meaning of life?" It is worth getting a bit more precise about what this involves. We might distinguish motivational priority and hermeneutical priority. What motivates our asking the question of life's meaning?-our concerns over origins, purpose, significance, value, worth, sense-making, suffering, and death. Our sense-making desire, then, is one

${ }_{17}$ Though, cf. footnote 15 . 
among many motivators. In this way, the question of life's meaning is about all of these. On this point, I agree with proponents of pluralist interpretive approaches.

However, on how best to interpret the traditional formulation of the life's meaning question, I think that viewing sense-making $\left(\mathrm{I}^{-\mathrm{M}_{\mathrm{EANIN}}}\right)$ as hermeneutically foundational is our most promising strategy. Why? Prioritizing sense-making meaning as I suggest allows us to retain the traditional formulation of the question as itself a singular, intelligible, answerable request. This in turn shows that people are not conceptually confused when asking the question in that form; they are asking something real and that makes sense on its own terms. My interpretation allows for this, the amalgam approach does not. Both my interpretation of the traditional formulation and the amalgam approach, however, do view the question as one about a lot of stuff. In this, they agree. But how can we bring it all together in a way that is sensitive to the linguistic contours of the traditional formulation of the life's meaning question? Whereas the amalgam approach lacks the necessary resources to do so, my approach does not.

The search for meaning is the search for a sense-making framework through which to fit together answers to our various existentially weighty questions and concerns about life (MofL). Importantly, this pursuit also tracks our desire to live a meaningful life (MinL). The epistemic and the normative, the theoretical and the practical, are inseparable in our search for meaning, and the sense-making framework that we seek links all of this as we pursue meaningful lives in light of our place within the grand scheme of it all. These considerations lead me to the position of meaning holism.

\section{Sense-making, existential longings, and God}

I close by returning to a tension acknowledged earlier in the paper, the tension between two kinds of sense-making. A salient part of the historical account of the rise of the question of life's meaning is connected with the ascendency of naturalism. Naturalism provides a metanarrative of the universe and in so doing makes sense of life. And yet many were (and many still are) prone to conclude that the kind of universe naturalism reveals is one that makes no sense. ${ }^{18}$ The tendency to see an absurdity here is the product of us being concerned as much with the meaning of life as we are with finding meaning in our individual lives. It is also the product of how our sense-making proclivities are uniquely contoured in this context, and

\footnotetext{
${ }^{18}$ Asking the question of life's meaning appears saliently tied to a kind of loss, the loss of a sort of transcendent sense-making that secured deep versions of purpose and significance and provided a powerful salve for existentially-inflicted wounds like suffering and death. For a significant portion of human history, there was an expectation by many, nurtured in a way of looking at the cosmos, that the universe is the product of powerful, benevolent, personal, transcendent intentionality. Such a view of the world is hospitable to getting a unique kind of sense-making, purpose, and significance-in a word meaning - as part of the deep fabric of reality because at the heart of reality is mind, intentionality, and value. As such, to ask, "What is the meaning of life?" might involve a kind of rhetoric of lament for an absolute cosmic meaning in which to live, move, have and interpret our being (cf. Acts 17:28), the kind of meaning that naturalism seems ill-equipped to provide. It may be, then, that the question in its traditional form becomes pressing precisely when this type of meaning appears to be lost, at that point when it no longer has any answer.
} 
where such contours are often saliently formed by religious or transcendent or otherwise cosmic-normative assumptions (even implicit ones) about the way the universe is, might, or "should" be.

To borrow from sociologist Peter Berger, in seeking life's meaning, many are attempting to locate it "within a sacred and cosmic frame of reference" of trying to plumb the connection "between microcosm and macrocosm" (Berger, 1967, p. 27). God, transcendence, and religion give our lives and their parts a deeper traction within a "sacred and cosmic frame," and allow for definitive resolution to the ills of this life. They provide a powerful fittingness between entrenched human longings and hopes and an ultimate ontologicalnormative architecture hospitable to them. The project of locating, framing, contextualizing, and situating our lives and their existentially weighty aspects is a project of sense-making, one whose focus is squarely on questions and concerns about origins, purpose, significance, value, suffering, and destiny. It is also laden with complex emotional and existential baggage that fashions the shape that sense-making takes in this context. Insofar as this sense-making pursuit has an ineliminable cosmic element, the human desire to make sense of life (and thereby acquire meaning) will also continue to stubbornly intersect with questions about transcendence, spirituality, religion, and God.

\section{Acknowledgement}

I thank Stewart Goetz, Timothy Mawson, Wendell O’Brien, Mirela Oliva, Lucas Scripter, Joshua Spears, participants and members of the audience at the April 2019 Harvard Interdisciplinary Meaning of Life Conference, and the editors of this journal for their incisive feedback on this paper. Finally, thanks to Lauren Weldon for designing the infographics.

\section{References}

Baggini, J. (2004). What's it all about? Philosophy \& the meaning of life. Oxford: Oxford University Press.

Berger, P. (1967). The sacred canopy. New York: Doubleday.

Camus, A. (1991). The myth of Sisyphus and other essays. New York: Vintage.

Dilthey, W. (1980). Gesammelte Schriften. In T. Plantinga, Historical understanding in the thought of Willhelm Dilthey (8, 208-209). Toronto: University of Toronto Press.

Gilovich, T. (1991). How we know what isn't so: The fallibility of human reason in everyday life. New York: The Free Press.

Hepburn, R. W. (1966). Questions about the meaning of life. Religious Studies, 1, 125-140.

Kahane, G. (2014). Our cosmic insignificance. Noûs, 48, 745-772.

King, L. A., Heintzelman, S. J., \& Ward, S. J. (2016). Beyond the search for meaning: A contemporary science of the experience of meaning in life. Current Directions in Psychological Science, 25, 211216.

Landau, I. (2011). The meaning of life sub specie aeternitatis. Australasian Journal of Philosophy, 89, 727-734.

Landau, I. (2014). Standards, perspectives, and the meaning of life: A reply to Seachris. Ethical Theory and Moral Practice, 17, 457-468.

MacIntyre, A. (2007). After virtue. (3rd Ed.). Notre Dame, IN: University of Notre Dame Press. 
Makkreel, R. A. (2001). Dilthey, Wilhelm. In R. Audi (Ed.), The Cambridge dictionary of philosophy (p. 236). Cambridge: Cambridge University Press.

Martela, F., \& Steger M. F. (2016). The three meanings of meaning in life: Distinguishing coherence, purpose, and significance. The Journal of Positive Psychology, 11, 531-545.

Mawson, T. (2016a). God and the meanings of life. London: Bloomsbury Academic.

Mawson, T. (2016b). What God could (and couldn't) do to make life meaningful. In J. W. Seachris and S. Goetz (Eds.), God and meaning: New essays (pp. 37-58). New York: Bloomsbury Academic.

Metz, T. (2007). New developments in the meaning of life. Philosophy Compass, 2, 196-217.

Munitz, M. K. (1993). Does life have a meaning? Buffalo, NY: Prometheus Books.

Russell, B. (1957). A free man's worship. In Why I am not a Christian and other essays on religion and related subjects. New York: Touchstone.

Seachris, J. W. (2013). The sub specie aeternitatis perspective and normative evaluations of life's meaningfulness: A closer look. Ethical Theory and Moral Practice, 16, 605-620.

Steger, M. F. (2012). Experie ncing meaning in life: Optimal functioning at the nexus of wellbeing, psychopathology, and spirituality. In P. T. P. Wong (Ed.), The human quest for meaning (pp. 165184). New York: Routledge.

Svendsen, L. (2005). A philosophy of boredom. (John Irons Trans.). London: Reaktion Books.

Wright, N. T. (2003). The resurrection of the son of God. Volume 3. Christian origins and the question of God. Minneapolis, MN: Fortress Press.

Center for Philosophy of Religion

223 Malloy Hall

University of Notre Dame

Notre Dame, IN 46556

USA

Email: jseachris@nd.edu 